\title{
Method Development and Validation for Quantitative Estimation of Calcium Acetate in Calcium Acetate Capsules by RP-HPLC using Indirect UV Method
}

\author{
Rajesh Kumar Chawla*, Subhranshu Panda, Kulandaivelu Umasankar, Siva Prasad Panda, Dalu \\ Damayanthi
}

K. L. College of Pharmacy, K. L. University, Vaddeswaram, Guntur, Andhra Pradesh, INDIA.

\begin{abstract}
Objective: A simple, accurate and economical method has been developed by Reverse Phase High Performance Liquid Chromatography (RP-HPLC) using indirect UV (Ultra Violet) method. The Principle behind the indirect UV method was applied; the copper sulfate pentahydrate with UV absorption in the mobile phase was replaced with calcium ions without UV absorption, resulting in a reduction in UV absorption of the mobile phase. Materials and Methods: Method development was carried out on strong cation exchanger column (Zorbax 300-SCX, $4.6 \mathrm{~mm}$ i.d. x $150 \mathrm{~mm}$, particle size $5 \mu \mathrm{m}$ ). The mobile phase consists of $4 \mathrm{mM}$ copper sulfate pentahydrate solution at a flow rate of 2.0 $\mathrm{mL}$ per min. Indirect UV detection was performed at $230.0 \mathrm{~nm}$. Results: Retention time for calcium was found about $7.1 \mathrm{~min}$. The developed method was validated in terms of specificity, linearity, accuracy, precision, range, limit of detection, limit of quantification and robustness. Calibration plot was linear over the concentration range of 19 to 1125 $\mu \mathrm{g} / \mathrm{mL}$. System suitability parameters were found $0.8 \% \mathrm{RSD}$, tailing factor 1.1 and more than 8000 theoretical plates. Limit of detection and limit of quantification were found $6.3 \mu \mathrm{g} / \mathrm{mL}$ and $19.0 \mu \mathrm{g} / \mathrm{mL}$ respectively. Conclusion: The high recovery and low relative standard deviation confirm the suitability of the method for determination of calcium acetate in calcium acetate capsules.
\end{abstract}

Key words: Calcium Acetate, RP-HPLC, Indirect UV method, Chromophore, Validation.

\section{INTRODUCTION}

Calcium acetate (Figure 1) is a calcium salt of acetic acid. Its standard name is calcium acetate and calcium ethanolate is the systematic name. Its anhydrous form is hygroscopic in nature. ${ }^{1}$ Calcium acetate is used to prevent high blood phosphate levels (called hyperphosphatemia) in patients who are on dialysis due to severe kidney disease. Dialysis removes some phosphate from the blood, but it is difficult to remove enough to keep the phosphate levels balanced. Decreasing blood phosphate levels can help keep the bones strong, prevent unsafe buildup of minerals in the body and possibly decrease the risk of heart disease and strokes that can result from high phosphate levels. Calcium acetate is a natural mineral that works by holding onto phosphate from the diet so that it can pass out of the body. ${ }^{2}$

Chromophore is covalently unsaturated group which is responsible for electronic absorption. The color usually appears in an organic compound if it contains certain unsaturated groups. These unsaturated groups are called chromophores and any compounds having this chromophore are called chromogen. ${ }^{3}$ Those compounds which are not having chromophore are very difficult to analyze by RP-HPLC using UV detector and can be analyzed by external derivatization, in situ derivatization or indirect UV methods.
Submission Date: 15-12-2018; Revision Date: 06-02-2019; Accepted Date: 27-03-2019

DOI: 10.5530/ijper.53.3s.109 Correspondence: Mr. Rajesh Kumar Chawla, K. L. College of Pharmacy, K. L. University, Vaddeswaram, Guntur-522502, Andhra Pradesh, INDIA.

Phone: +918074836561 E-mail: rbchawla07@gmail. com

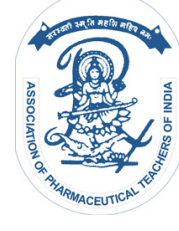

www.ijper.org 
Calcium acetate structure does not have any chromophore, hence it does not shows any absorbance in UV-Visible range. The literature survey revealed that calcium acetate assay in active pharmaceutical ingredient and tablets has been reported by titrimetry in United State Pharmacopoeia. ${ }^{4}$ The atomic absorption spectroscopy method has been reported in United States Pharmacopoeia for dissolution of calcium acetate tablets. ${ }^{5}$ European pharmacopoeia also reported assay of calcium acetate by complexometric titration of calcium. ${ }^{6}$ Few methods are reported for determination of calcium in serum by atomic absorption spectroscopy. ${ }^{7,8}$ Calcium determination by flame photometry is also reported., ${ }^{910}$ Some methods are reported estimation of calcium by Inductively coupled plasma-mass spectroscopy (ICPMS). ${ }^{11,12}$ It was observed that there is no method available for quantitative estimation of calcium acetate in calcium acetate capsules by RP-HPLC using UV detector, hence the present work was undertaken to develop and validate a simple, accurate and economical method by RP-HPLC using UV detector which can be used for routine analysis in quality control and research laboratory for assay of calcium acetate in capsules.

\section{MATERIALS}

Copper sulfate pentahydrate (ACS grade, EC No. 231 847-6) was procured from Merck Millipore, India. Calcium acetate working standard (secondary standard traceable to USP) was procured from Sigma-Aldrich (Catalog No. PHR1362). HPLC grade water was used from Milli-Q water purifier system. The marketed calcium acetate capsule formulation (Calcium Acetate Gelcaps 667mg, Make: Fresenius Medical Care, North America) was used for analysis of drug product.

\section{METHODS}

The method was developed and validated on Agilent's 1260 Infinity II series automated HPLC system with UV detector using EZChrome Elite software, version 3.3.2 SP2. The method used to estimate calcium is indirect UV method. ${ }^{13}$ The chromatographic parameters were optimized and optimized chromatographic conditions are shown in Table 1.

\section{Mobile phase (4 mM Copper sulfate pentahydrate solution)}

Dissolved $1000 \mathrm{mg}$ of copper sulfate pentahydrate in $1000 \mathrm{~mL}$ of HPLC grade water and filtered through $0.45 \mu \mathrm{m}$, nylon 6,6 membrane filter and degassed under sonication for $10 \mathrm{~min}$.

\section{Diluent and blank}

Used HPLC grade water as diluent and blank.

\section{Standard preparation (about $750 \mu \mathrm{g} / \mathrm{mL}$ )}

Weighed accurately and transferred $75.0 \mathrm{mg}$ of calcium acetate working standard in to a $100 \mathrm{~mL}$ volumetric flask. Added $70 \mathrm{~mL}$ of diluent, sonicated to dissolve and made volume up to mark with diluent. Filtered the solution through $0.45 \mu \mathrm{m}$ Polyvinylidene Fluoride (PVDF) syringe filter by discarding about first $3 \mathrm{~mL}$ of filtrate.

\section{Check standard preparation (about $750 \mu \mathrm{g} / \mathrm{mL}$ )}

Weighed accurately and transferred $75 \mathrm{mg}$ of calcium acetate working standard in to a $100 \mathrm{~mL}$ volumetric flask. Added $70 \mathrm{~mL}$ of diluent, sonicated to dissolve and made volume up to mark with diluent. Filtered the solution through $0.45 \mu \mathrm{m}$ Polyvinylidene Fluoride (PVDF) syringe filter by discarding about first $3 \mathrm{~mL}$ of filtrate.

\section{Test sample preparation (about $750 \mu \mathrm{g} / \mathrm{mL}$ )}

Crushed 20 capsules content in fine powder. Weighed accurately and transferred capsule powder equivalent to $150 \mathrm{mg}$ of calcium acetate in to a $200 \mathrm{~mL}$ volumetric flask. Added $170 \mathrm{~mL}$ of diluent, sonicated for $20 \mathrm{~min}$ with intermittent shaking and made volume up to mark with diluent. Filtered the solution through $0.45 \mu \mathrm{m}$ Polyvinylidene Fluoride (PVDF) syringe filter by discarding about first $3 \mathrm{~mL}$ of filtrate.

\section{Method validation}

The developed method was validated as per International Conference on Harmonization (ICH) Q2 (R1) ${ }^{14}$ guidelines and United States Pharmacopoeia general chapter $<1225>{ }^{15}$

\section{System suitability}

System suitability was checked in accordance with United States Pharmacopoeia general chapter $<621>{ }^{16}$

$\%$ relative standard deviation for six replicate standard, similarity factor for check standard, tailing factor and theoretical plate count of calcium peak were evaluated.

\section{Specificity}

The developed method was validated for specificity by injecting blank and placebo solution in triplicate. The chromatograms were evaluated for any interference at the retention time of calcium peak.

\section{Precision}

Precision of the development method was evaluated by injecting six test sample preparations from a homogenous fine capsule powder. $\%$ assay and $\%$ relative standard deviation of six test samples were calculated for 
calcium acetate. Intermediate precision of the method was also evaluated using different analyst, different HPLC system and different column by injecting six test sample prepared as same for precision. The acceptance criteria for individual precision \% RSD was not more than 2.0 and for 12 assay results was not more than 3.0. The mean assay difference of individual precision was not more than $2.0 \%$.

\section{Accuracy (Recovery)}

Recovery study was performed to evaluate the accuracy of the method by spiking method. Recovery study was done by spiking calcium acetate standard in to placebo in the concentration of $50 \%, 100 \%$ and $150 \%$ level of the proposed concentration. The test samples were prepared in triplicate at each level and injected in the proposed chromatographic conditions. \% recovery of calcium acetate was calculated for all the levels. The acceptance criterion for recovery of calcium acetate was 98.0 to $102.0 \%$ and $\%$ RSD for nine recovery results was not more than 2.0.

\section{Limit of Detection (LOD) and Limit of Quantitation (LOQ)}

LOD and LOQ were determined by standard deviation of the response and slope method. The linearity was performed from 5 to $100 \%$ of the proposed concentration by diluting standard solution. LOD and LOQ were determined by using following formulae:

$\mathrm{LOD}=3.3 \times(\sigma / \mathrm{S})$

$\mathrm{LOQ}=10 \times(\sigma / \mathrm{S})$

Where $\sigma=$ standard deviation of response and $\mathrm{S}=$ slope determined from calibration curve of linear plot.

\section{Linearity}

Linearity of the method was established for calcium acetate from LOQ to $150 \%$ of the proposed concentration using nine calibration levels (LOQ, 5, 10, 25, 50, 75, 100,125 and $150 \%$ ) from the range LOQ to $1125 \mu \mathrm{g} /$ $\mathrm{mL}$. The working standard was used to prepare calibration levels. The calibration curve was plotted for each level as concentration of level verses peak response. The result of linearity was evaluated by regression analysis.

\section{Robustness}

For robustness study, three chromatographic parameters were considered such as (i) concentration of mobile phase $\pm 10 \%$ (3.6 and $4.4 \mathrm{mM}$ copper sulfate pentahydrate solution), (ii) flow rate $\pm 10 \%(1.8$ and $2.2 \mathrm{~mL} /$ min) and (iii) column temperature $\pm 5^{\circ} \mathrm{C}\left(20^{\circ} \mathrm{C}\right.$ and $30^{\circ} \mathrm{C}$ ). Robustness of the method was evaluated by system suitability and assay of formulation.

\section{Solution stability}

Solution stability was established for standard and test sample preparations. Bench-top (ambient temperature) stability was established by injecting standard and test sample at regular interval for seven days. Solution stability was established by calculating similarity factor for standard against fresh standard and \% assay difference for test sample from initial assay.

\section{RESULTS AND DISCUSSION}

\section{Method development}

The Principle behind the indirect UV method was applied; the copper sulfate pentahydrate with UV absorption in the mobile phase was replaced with calcium ions without UV absorption, resulting in a reduction in UV absorption of the mobile phase. ${ }^{13}$ Several trials were taken to optimize the concentration of copper sulfate pentahydrate, flow rate and injection volume to achieve good peak shape and better retention of calcium peak. It was observed that the concentration of copper sulfate pentahydrate is indirectly proportional to retention of calcium peak. The most optimized chromatographic conditions are summarized in Table 1.

\section{System suitability}

System suitability of the method was evaluated by means of $\%$ relative standard deviation for six replicate standard, similarity factor for check standard, tailing factor

\begin{tabular}{|c|c|}
\hline Table 1: Optimized Chromatographic Conditions of the Developed Method. \\
\hline Parameter & Optimized Condition \\
\hline Mobile phase & $4 \mathrm{mM}$ Copper sulfate pentahydrate solution \\
Column & Zorbax 300-SCX, $4.6 \mathrm{~mm}$ X 150 mm, $5 \mu$ \\
& (Part No. 883952-704, Make: Agilent) \\
Flow rate & $2.0 \mathrm{~mL} / \mathrm{min}$ \\
UV detectorwavelength & $230 \mathrm{~nm}$ \\
Detector polarity & Negative $(-)$ \\
Injection volume & $10 \mu \mathrm{L}$ \\
Column temperature & $25^{\circ} \mathrm{C}$ \\
Run time & $15 \mathrm{~min}$ \\
Mode & Isocratic \\
\hline
\end{tabular}


and theoretical plate count of calcium peak and found within the acceptance criteria. The results are presented in Table 2.

\section{Specificity}

The specificity was performed to check blank and placebo interference. The chromatograms show (Figures 2-5) no interference at the retention time of calcium peak due to blank and placebo.

\section{Precision}

Precision of the method was evaluated by injecting six test sample preparations from a homogenous fine capsule powder and $\%$ RSD of assay $(n=6)$ was found to be 0.6 , whereas for intermediate precision it was found to be $0.5 . \%$ RSD of precision and intermediate precision $(n=12)$ was found to be 0.6 . The mean $\%$ assay difference was found to be 0.4 between precision and intermediate precision. The results were found within acceptance criteria for precision of the developed method. The results of precision are compiled in Table 3.

\section{Accuracy (Recovery)}

The accuracy was evaluated by calculating the recoveries at $50 \%, 100 \%$ and $150 \%$ level of the proposed concentration and the mean $\%$ recoveries $(n=3)$ were found to be $98.0,99.0$ and 100.0 respectively. The mean $\%$ recov-

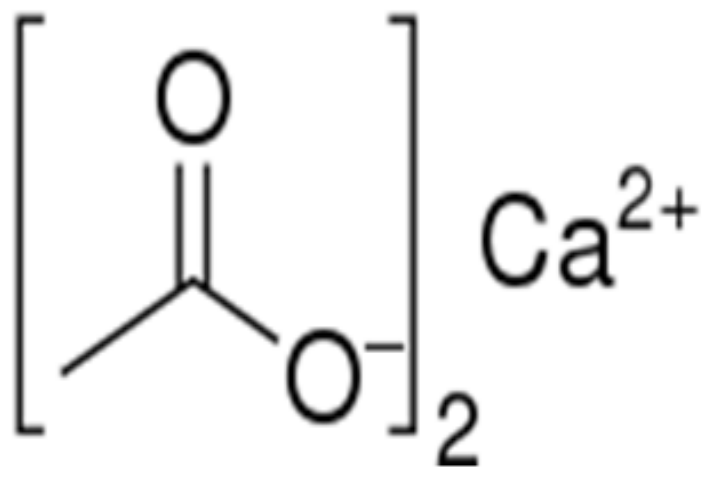

Figure 1: Structure of Calcium acetate.

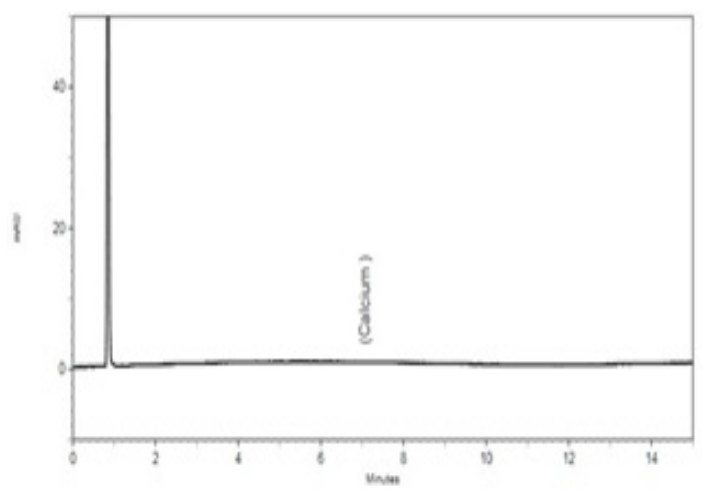

Figure 2: Chromatogram of blank. ery of all levels $(n=9)$ was found to be 100.0 with $0.5 \%$ RSD. The recoveries were found within the acceptance criteria and method found to be accurate. The results of accuracy are presented in Table 4.

\section{LOD and LOQ}

LOD and LOQ were determined by standard deviation of the response and slope method. The LOD and LOQ of the method were found to be $6.3 \mu \mathrm{g} / \mathrm{mL}$ and 19.0 $\mu \mathrm{g} / \mathrm{mL}$ respectively.

\section{Linearity}

The developed method was found to be linear from LOQ to $150 \%$ of the proposed concentration over

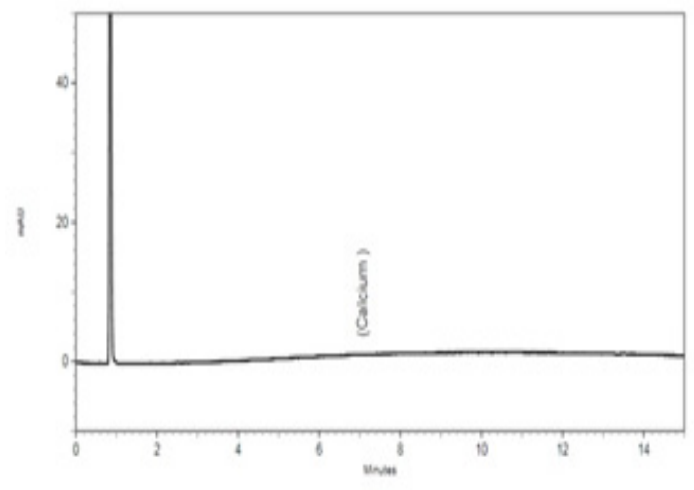

Figure 3: Chromatogram of placebo.

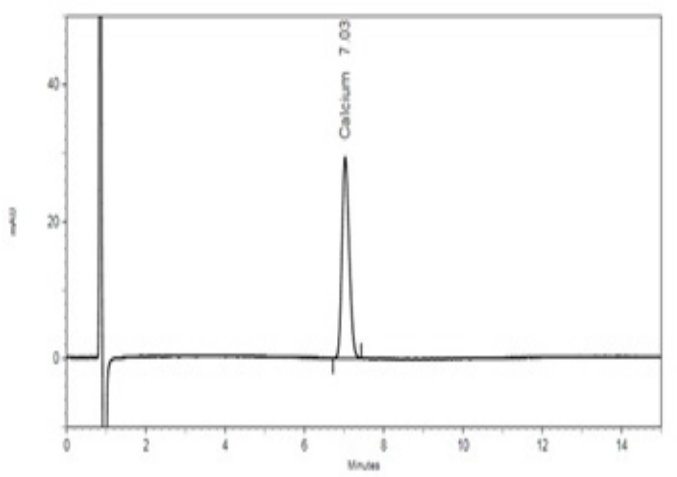

Figure 4: Chromatogram of standard.

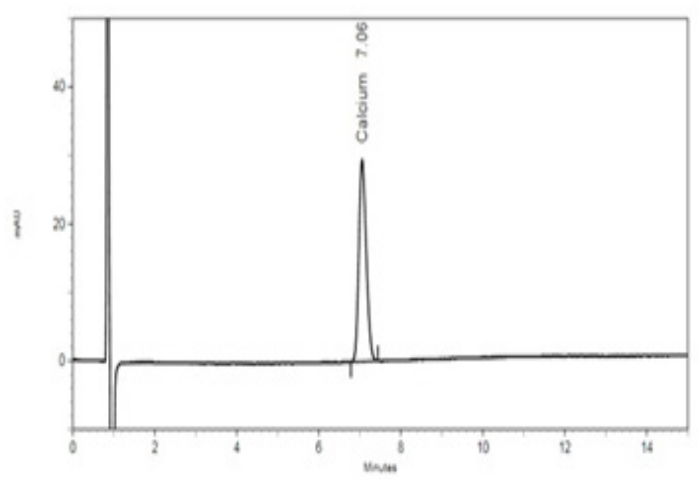

Figure 5: Chromatogram of test sample. 
nine calibration levels ranging from $19 \mu \mathrm{g} / \mathrm{mL}$ (LOQ) to $1125 \mu \mathrm{g} / \mathrm{mL}$. The value of correlation coefficient $\left(r^{2}\right)$ was found to be 1.000. Linearity graph of calcium acetate is shown in Figure 6. Chromatograms at LOQ and $150 \%$ are shown in Figure 7-8.

\begin{tabular}{|c|c|}
\hline \multicolumn{2}{|c|}{ Table 2: System Suitability Results. } \\
\hline Parameter & Result \\
\hline & \\
Retention time (min) & 7.1 \\
\% RSD of six replicate standard & 0.8 \\
Check standard (similarity factor) & 1.00 \\
Tailing factor & 1.1 \\
Theoretical plates & 8123 \\
& \\
\hline
\end{tabular}

\begin{tabular}{|c|c|c|}
\hline \multicolumn{3}{|c|}{ Table 3: Precision Results. } \\
\hline Test sample No. & $\begin{array}{c}\text { Precision (\% } \\
\text { assay) }\end{array}$ & $\begin{array}{c}\text { Intermediate precision } \\
\text { (\% assay) }\end{array}$ \\
\hline 01 & 99.1 & 100.6 \\
02 & 98.6 & 99.3 \\
03 & 100.1 & 100.2 \\
04 & 99.2 & 00.8 \\
05 & 99.8 & 99.6 \\
06 & 99.9 & 99.8 \\
Mean $(n=6)$ & 99.5 & 99.9 \\
$\%$ RSD $(n=6)$ & 0.6 & 0.5 \\
Mean $(n=12)$ & & 99.7 \\
$\%$ RSD $(n=12)$ & & 0.5 \\
Mean \% difference & & 0.4 \\
\hline
\end{tabular}

\begin{tabular}{|c|c|c|c|c|}
\hline \multicolumn{5}{|c|}{ Table 4: Accuracy Results. } \\
\hline $\begin{array}{c}\text { Recovery } \\
\text { level }\end{array}$ & $\begin{array}{c}\text { Test } \\
\text { No. }\end{array}$ & Recovery (\%) & Mean (\%) & $\%$ RSD \\
\hline $50 \%$ & 1 & 99.6 & & \\
$50 \%$ & 2 & 99.7 & 99.0 & 0.4 \\
$50 \%$ & 3 & 100.3 & & \\
$100 \%$ & 1 & 100.4 & 100.4 & 0.3 \\
$100 \%$ & 2 & 100.0 & & \\
$100 \%$ & 3 & 100.7 & 100.4 & \\
$150 \%$ & 1 & 99.4 & 100.0 & 0.5 \\
$150 \%$ & 2 & 100.2 & & \\
$150 \%$ & 3 & 100.1 & 0.4 \\
\hline
\end{tabular}

\section{Robustness}

The robustness of method was evaluated by changing critical chromatographic parameters like concentration of mobile phase, flow rate and column temperature. Robustness results were found within the acceptance criteria and presented in Table 5.

\section{Solution stability}

Solution stability of calcium acetate standard and test sample solution was established and found to be stable for seven days on bench-top (ambient temperature). Similarity factor for standard after seven days was found to be 0.99 and \% assay difference for test sample from initial assay was found to be 0.3 .

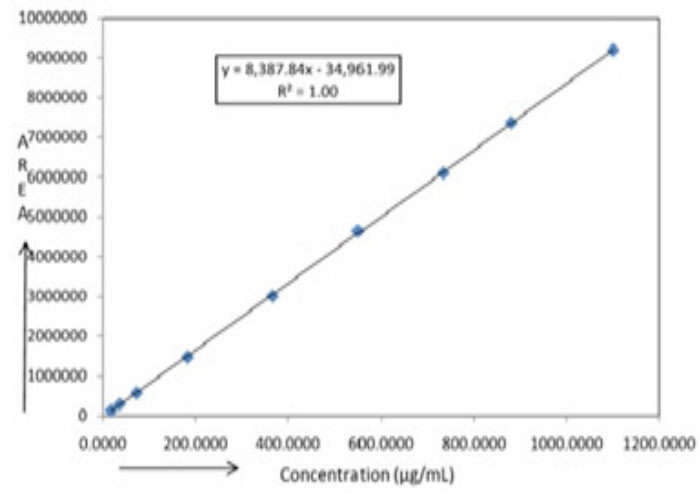

Figure 6: Linearity graph of calcium acetate.

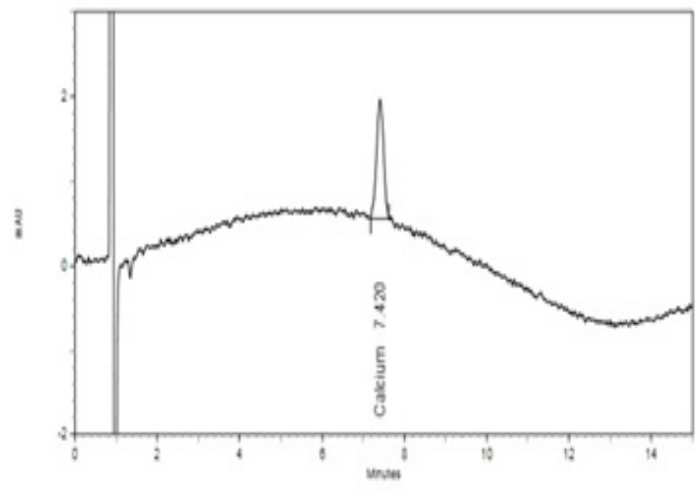

Figure 7: Chromatogram at LOQ level.

\begin{tabular}{|c|c|c|c|c|c|}
\hline \multicolumn{7}{|c|}{ Table 5: Robustness Results. } \\
\hline Chromatographic Parameters & $\begin{array}{c}\text { Retention time } \\
\text { (min) }\end{array}$ & $\begin{array}{c}\text { \% RSD of } \\
\text { standard }\end{array}$ & $\begin{array}{c}\text { Tailing } \\
\text { factor }\end{array}$ & $\begin{array}{c}\text { Theoretical } \\
\text { plates }\end{array}$ & \% Assay \\
\hline As such method & 7.1 & 0.7 & 1.1 & 8156 & 99.9 \\
3.6 mM Copper Sulfate Pentahydrate & 7.4 & 0.5 & 1.1 & 8594 & 99.3 \\
$4.4 \mathrm{mM}$ Copper Sulafte Pentahydrate & 6.9 & 0.7 & 1.2 & 7634 & 99.6 \\
Flow rate $1.8 \mathrm{~mL} / \mathrm{min}$ & 7.7 & 0.8 & 1.2 & 8310 & 100.2 \\
Flow rate 2.2 $\mathrm{mL} / \mathrm{min}$ & 6.5 & 0.8 & 1.1 & 7826 & 99.7 \\
Column temp. $20^{\circ} \mathrm{C}$ & 7.4 & 0.6 & 1.2 & 8130 & 99.5 \\
Column temp. $30^{\circ} \mathrm{C}$ & 6.9 & 0.5 & 1.1 & 7893 & 99.8 \\
\hline
\end{tabular}




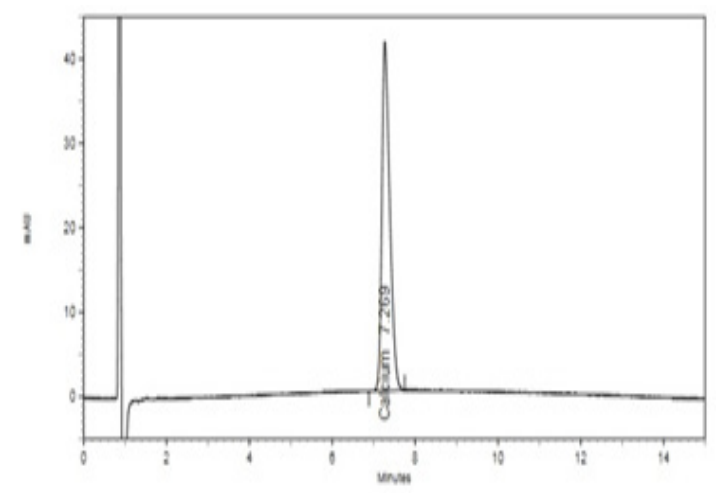

Figure 8: Chromatogram at $150 \%$ level.

\section{CONCLUSION}

The developed method was validated as per ICH and USP guidelines for specificity, precision, accuracy, linearity and robustness over the range of 325 to $1125 \mu \mathrm{g} /$ $\mathrm{mL}$ and found meeting the acceptance criteria for all parameters. The proposed method is innovative, simple, accurate, robust and economical method for quantitative estimation (assay) of calcium acetate in calcium acetate capsules by RP-HPLC using UV detector can be used for routine analysis in quality control and research laboratory as an economical and easy alternative to the more sophisticated and expensive to run instruments.

\section{ACKNOWLEDGEMENT}

The authors express their thanks to Suven Life Sciences Limited, Hyderabad for support and providing the research facility to carrying out the work.

\section{CONFLICT OF INTEREST}

The authors declare no conflict of interest.

\section{ABBREVIATIONS}

RP-HPLC: Reverse Phase High Performance Liquid Chromatography; UV: Ultra Violet; ICH: International Conference on Harmonization; USP: United States Pharmacopoeia; LOQ: Limit of Quantitation; LOD: Limit of Detection; RSD: Relative Standard Deviation; mM: Millimolar; $\boldsymbol{n = 6 : ~ N u m b e r ~ o f ~ t e s t ~ s a m p l e s ~}=6$; $\mathbf{n}=\mathbf{1 2}$ : Number of test samples $=12 ; \mathbf{n}=\mathbf{9}$ : Number of test samples $=9$.

\section{REFERENCES}

1. https://en.wikipedia.org/wiki/Calcium_acetate

2. https://www.webmd.com/drugs/2/drug-10696/calcium-acetate-oral/details

3. Sharma BK. Spectroscopy, 2007; $20^{\text {th }}$ edition, GOEL Publication House 2007; S125. S-125.https://books.google.co.in/books/about/Spectroscopy. html?id=qYEw OKqNCwC.

4. United States Pharmacopoeia 41- NF36, The U.S. Pharmacopoeial Convention 2018; Official Monographs. Calcium Acetate and Calcium Acetate Tablets:627-630.

5. United States Pharmacopoeia 41- NF36, The U.S. Pharmacopoeial Convention 2018; Official Monographs.Calcium Acetate Tablets: 2017;191011.

6. European Pharmacopoeia 9.0, Council of Europe 2017; Monographs, Calcium Acetate:1910-1911.

7. Sudhakar K, Sujatha M, Ramesh BS, Padmavathi P, Reddy PP. Serum calcium levels in patients with essential hypertension and their first degree relatives. Indian J of Clin Biochemistry. 2004;19(1):21-3. https://www.ncbi. nlm.nih.gov/pmc/articles/PMC3453899/.

8. Maqueda C, Morillo E. Determination of calcium by atomic absorption spectrometry in samples dissolved by acid mixtures. $J$ of Anal Chem.1990;338(3):253-4. https://link.springer.com/article/10.1007/ BF00323018.

9. Baker RWR. The determination of calcium in serum by flame photometry. Biochem J. 1995;59(4):566-71.. https://www.ncbi.nlm.nih.gov/pmc/articles/ PMC1215619/.

10. The simple Flame Photometric determination of Calcium, Bibby Scientific, Protocol: P05-011A http://www.jenway.com/adminimages/P05_011A_ Determination_of_Calcium.pdf.

11. Chen Z, Griffin IJ, Kriseman Y, Liang LK, Abrams SA. Inductively Coupled Plasma Mass Spectrometric analysis of Calcium Isotopes in Human Serum: A low-sample-volume Acid-Equilibration Method. Clinical Chemistry. 2003;49(12):2050-5. https://www.ncbi.nlm.nih.gov/pubmed/14633877

12. Lee A, Yang V, Hsu J, Wu E, Shih R. Ultratrace measurement of calcium in ultrapure water using the agilent 8800 Triple quadrapole ICP-MS. Aplication note, Agilent Technologies, Tokyo, Japan. https://www.agilent.com/cs/ library/applications/5991-1693EN_AppNote_ICP-MS_8800_semicon_Ca_ ultrapure_water.pdf.

13. Shintani H. Improvement of ion chromatography with ultraviolet photometric detection and comparison with conductivity detection for the determination of serum cations. J of Chrom. B: Biomedical Sci and Appl. 1985;341:53-63. https://www.sciencedirect.com/science/article/pii/S0378434700840098

14. International Conference on Harmonisation, Harmonized Triplicate Guideline 2005, Validation of analytical procedures: text and methodology: Q2(R1). http://www.ich.org/fileadmin/Public_Web_Site/ICH_Products/Guidelines/ Quality/Q2_R1/Step4/Q2_R1 Guideline.pdf Accessed October 20, 2018.

15. United States of Pharmacopoeia 41- NF36, United States Pharmacopeial Convention 2018, General chapter <1225>, Validation of Compendial Procedures.

16. United States of Pharmacopoeia 41- NF36, United States Pharmacopeial Convention 2018, General Chapter <621 $>$, Chromatography.

Cite this article: Chawla RK, Panda S, Umasankar K, Panda SP, Damayanthi D. Method Development and Validation for Quantitative Estimation of Calcium Acetate in Calcium Acetate Capsules by RP-HPLC using Indirect UV Method. Indian J of Pharmaceutical Education and Research. 2019;53(3 Suppl 2):s380-s386. 


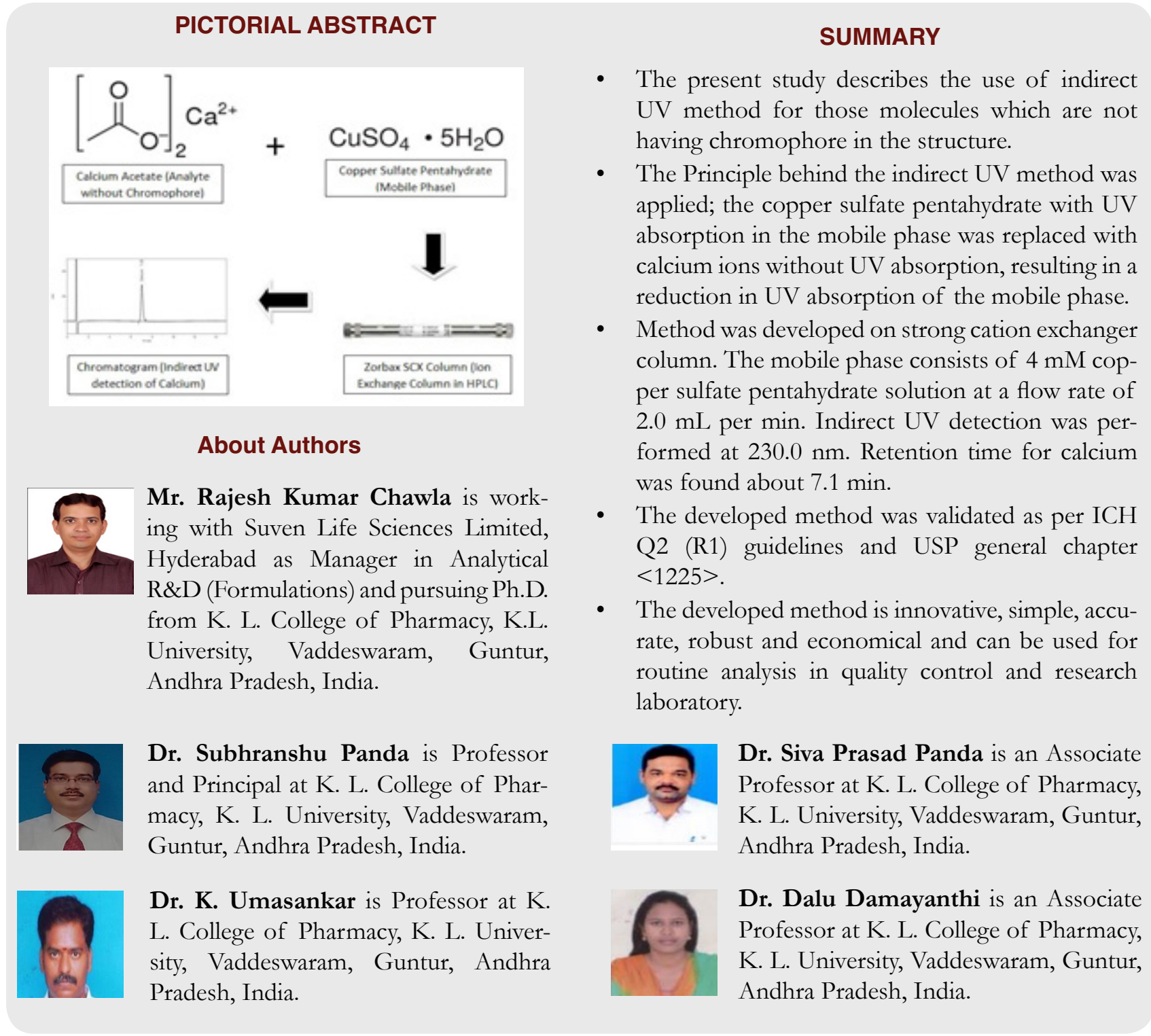

